\title{
Wnt-induced proteolytic targeting
}

\author{
Katherine A. Jones ${ }^{1}$ and Caroline R. Kemp \\ Regulatory Biology Laboratory, The Salk Institute for Biological Studies, La Jolla, California 92037, USA
}

\begin{abstract}
Misregulation of the Wnt pathway is a common route to cancer, including primary breast cancers. In this issue of Genes \& Development, Miranda-Carboni and colleagues (pp. 3121-3134) demonstrate that the cyclin-dependent kinase inhibitor $\mathrm{p} 27^{\mathrm{Kip} 1}$ is ubiquitylated for proteasomal degradation in Wnt10b-induced mammary tumors exclusively by the Cul4A E3 ligase, which is strongly induced by Wnt signaling. The discovery of a new Wntinduced proteolytic targeting system has important implications for the mechanism of Wnt-initiated tumorigenesis.
\end{abstract}

Wnt signaling, which is notoriously deregulated in colon cancer, has been implicated in breast cancer since the 1980s, when Wnt1 was first recognized as a mammary oncogene in studies of mouse mammary tumor virus (MMTV)-infected mice (Nusse and Varmus 1982; Tsukamoto et al. 1988). The Wnts are a large family of extracellular signaling molecules with partially redundant functions, and mouse mammary tumors also arise from insertional activation of other Wnt genes, including Wnt3 or Wnt10b (Lane and Leder 1997; Howe and Brown 2004). Wnt10b-induced mouse mammary tumors are phenotypically diverse and express a variety of stem cell markers, similar to human basal-like breast carcinomas, and are thought to originate from stem/progenitor cells in the mammary gland.

An interesting new study by Miranda-Carboni et al. (2008) reports that the cyclin-dependent kinase inhibitor $\mathrm{p} 27^{\mathrm{Kip} 1}(\mathrm{p} 27)$ is down-regulated in Wnt10b-induced mouse mammary tumors. Nuclear p 27 is a potent tumor suppressor that arrests the cell cycle at a checkpoint for entry into $S$ phase, and loss of p27 is commonly observed in human cancers (Chu et al. 2008). Whereas tumor suppressors are often silenced epigenetically or mutated in cancer, p27 is instead often regulated at the level of nuclear export or protein turnover. In some cancers, and during S-phase progression in normal cells, p27 is polyubiquitylated by the $\mathrm{SCF}^{\mathrm{Skp} 2} \mathrm{E} 3$ ligase for proteolytic destruction through the proteasome. Interestingly, Miranda-Carboni et al. (2008) found that Skp2 levels are low

[Keywords: Basal-like breast cancer; reprogramming; Wnt-induced proteasome targeting (WIPT); mammary progenitor cells; mammary stem cell (MSC); Cdknlb]

${ }^{1}$ Corresponding author

E-MAIL jones@salk.edu; FAX (858) 535-8194.

Article is online at http://www.genesdev.org/cgi/doi/10.1101/gad.1741008. in primary Wnt10b mammary tumors and that a phosphorylation-defective mutant p27 protein (T187A), which cannot bind $\mathrm{SCF}^{\mathrm{Skp} 2}$, is readily degraded in Wnt signaling cells. Further characterization of these tumors, described below, revealed that Wnt signaling induces the expression and activity of the Cul4 E3 ligase, which targets p27 for destruction during $S$ phase (Fig. 1). Cul4:Ddb1 is a nuclear and chromatin-targeted E3 ligase that regulates genome integrity, cell cycle progression, DNA replication, and the cellular response to DNA damage, global histone methylation (H3K4me1,3, H3K9me3, and $\mathrm{H} 3 \mathrm{~K} 27 \mathrm{me} 3$ ), as well as protein translation through the mammalian target of rapamycin (mTOR) pathway (Higa and Zhang 2007; O'Connell and Harper 2007). Consequently, the observation that Wnt signaling activates the Cul4A E3 ligase has broad implications for the mechanism of Wnt-induced cell transformation.

\section{Wnt signaling in breast cancer}

The canonical Wnt signaling pathway controls progenitor cell proliferation and cell fate decisions during development (Grigoryan et al. 2008; Huang and He 2008) and is required for maintenance of embryonic, adult and cancer stem cells (Reya et al. 2004; Reya and Clevers 2005; Blanpain et al. 2007; Barker et al. 2008). The Wnt pathway is also deregulated and constitutively active in various cancers, including colon cancer, melanoma, and hepatocellular and non-small-cell lung cancers. Canonical Wnt signaling stabilizes the transcriptional coactivator, $\beta$-catenin, which forms heterodimers with LEF-1/TCF DNA-binding proteins to activate Wnt target genes. The primary molecular target of Wnt signaling is the $\beta$-catenin "destruction complex," which contains the GSK3 $\beta$ protein kinase, the adenomatous polyposis coli (APC) tumor suppressor, and Axin, a scaffolding protein (McCartney and Näthke 2008). In nonsignaling cells, $\beta$ catenin is phosphorylated by CKI $\alpha$ and GSK3 $\beta$, and ubiquitylated by the $\beta$-TrCP E3 ligase for proteolytic degradation. The $\beta$-catenin destruction complex is temporarily disabled in Wnt signaling cells due to the activation of Dishevelled, a regulatory protein that inhibits GSK3 $\beta$ phosphorylation of cytoplasmic $\beta$-catenin, and stimulates GSK3 $\beta$ phosphorylation of the Frizzled:Lrp5/6 receptor complex at the membrane. Most colorectal cancers express a truncated form of the APC tumor suppressor that is unable to participate in the de- 
Figure 1. Wnt-induced Cul4A:Ddb1 E3 ubiquitin ligase exclusively targets $\mathrm{p} 27^{\mathrm{Kip} 1}$ for proteolysis in Wntdependent tumors. Cul4A engages an E1 activating enzyme, which transfers ubiquitin transfer to an E2 conjugating enzyme. The ubiquitin on E2 is transferred by the Cul4 E3 ligase to the substrate, p2 $7^{\text {Kip } 1}$, a tumor suppressor that blocks entry into the $S$ phase of the cell cycle. The adaptor protein Ddb1 binds various DWDcontaining WD40 proteins, which function as substrate receptors. Miranda-Carboni et al. (2008) show that Cul4 is directly regulated by Wnt signals and targets p $27^{\text {Kipl }}$ for ubiquitylation-proteolysis in Wnt10b-induced mouse mammary tumors, promoting cell cycle progression. The identity of the WD40 substrate receptor that links Cul4:Ddb1 to $27^{\text {Kip } 1}$ is currently unknown.

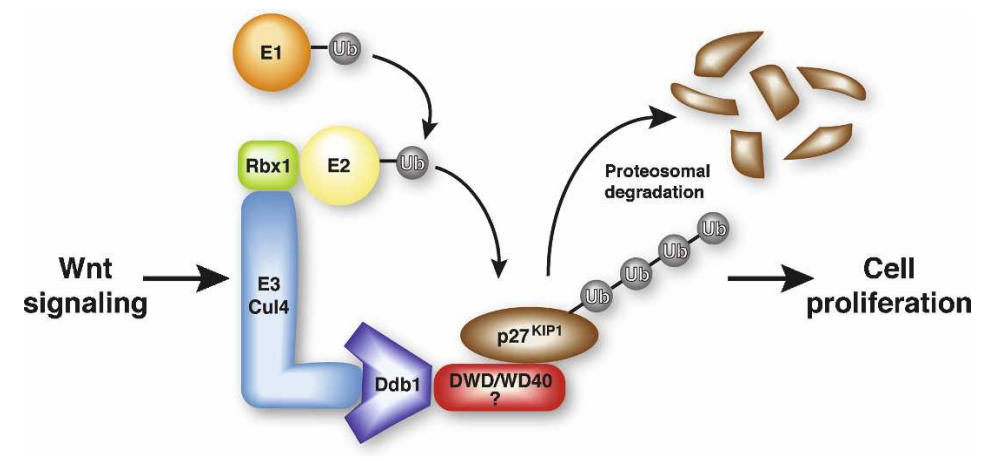

struction complex, or a mutated form of $\beta$-catenin that cannot be phosphorylated by GSK3 $\beta$, either of which is sufficient to permanently activate Wnt target genes.

Although $A P C$ mutations are rare in breast cancer, many primary mammary tumors, including basal/stem cell-like carcinomas, contain high levels of nuclear $\beta$ catenin and constitutively express Wnt target genes. Wnt signaling enhances the proliferation and self-renewal of mammary progenitor cells, and chronic stimulation of the pathway increases the stem cell population that gives rise to mammary tumors (Lindvall et al. 2007). Basal carcinomas are a heterogeneous collection of invasive breast cancers that constitute $10 \%-15 \%$ of human breast cancers, most of which are classified as "triplenegative" based upon the absence (or very low expression) of estrogen, progesterone, and HER2/Neu (ErbB2) receptors. These cancers appear to originate from Wntstimulated mammary progenitor cells within the stem cell niche and generally express high levels of EGFR, c-Myc, CycD1, as well as various stem cell markers and markers of mammary epithelial and myoepithelial cells. In breast and colon cancer, loss of p27 is associated with resistance to chemotherapy, increased metastasis, and a relatively poor prognosis.

\section{Regulated destruction of the $\mathrm{p} 27^{\mathrm{Kip} 1}$ tumor suppressor in Wnt signaling cells}

In the current study, Miranda-Carboni et al. (2008) examined mammary tumors from MMTV-Wnt10b transgenic mice by immunohistochemical staining and expression profiling, and found that these tumors express high levels of nuclear $\beta$-catenin and CycD1, but low levels of p27 and Skp2. In contrast, p27 levels were not significantly reduced in mouse mammary tumors derived from MMTV-ErbB2/Her2 transgenic mice. Downregulation of $\mathrm{p} 27$ could also be initiated by Wnt signaling in MEF cells isolated from $S k p 2^{-/-}$-null mice, and in mouse or human cells expressing variants of p27 that lack the Skp2-binding site. SCF ${ }^{\text {Skp2 }}$-independent p27 turnover was observed both in primary mammary tumor tissues, as well as in cultured cells lines (293T and MCF7) stimulated with $\mathrm{LiCl}$, a Wnt mimetic. Microarray data pointed to Cul4A and Cul4B as candidates for the Wnt- induced p27-specific E3 ligase, and follow-up studies showed that siRNA-mediated depletion of Cul4A blocked p27 turnover in vivo and delayed progression of the mammary epithelial cells through $S$ phase. In addition, dominant-negative Cul4 proteins effectively stabilized p27 throughout S phase in Wnt signaling MCF-7 cells. Chromatin immunoprecipitation experiments further revealed that $\beta$-catenin and LEF/TCF are recruited to the Cul4A promoter in Wnt signaling cells, raising the possibility that $C u 14 A$ is a direct Wnt target gene. These findings support and significantly extend earlier reports that p27 is a physiological substrate for Cul4A:Ddb1, both in flies and mammals (Bondar et al. 2006; Cang et al. 2006; Higa et al. 2006). More broadly, these data identify Cul4A:Ddb1 as the primary E3 ligase responsible for p27 destruction in basal breast carcinomas and in Wnt signaling mammary epithelial cells (Fig. 1) and establish that Cul4:Ddb1 ubiquitin ligase activity is strongly upregulated during $\mathrm{S}$ phase in Wnt signaling cells.

Enhanced turnover of p27 has also been observed previously in gastrointestinal tumors that develop in $A P C$ mutant Min/+ mice, which constitutively activate the Wnt/ $\beta$-catenin pathway, and loss of p27 is associated with tumor progression (Philipp-Staheli et al. 2002). In contrast, p27 levels are not affected in colorectal tumors of Smad3 mutant mice, which do not activate Wnt signaling, and germline deletion of $\mathrm{p} 27$ in these mice does not affect tumor initiation or progression. Moreover, expression of a p27 mutant (T187A) that blocks ubiquitylation by Cul1, but not Cul4A, in mouse tumor models for lung or colon cancer did not significantly affect tumor incidence or survival, indicating that $\mathrm{SCF}^{\mathrm{Skp} 2}$ is not the predominant regulator of $\mathrm{p} 27$ turnover in these tumors (Timmerbeul et al. 2006). Thus it will be interesting to learn whether Cul4:Ddb1 regulates p27 stability in colon and other Wnt-initiated cancers, and whether induction of Cul4A and Cul4B is a conserved feature of all Wnt signaling cells.

\section{What is Cul4:Ddb1?}

Cul4A and Cul4B belong to a large family of cullin-type E3 ubiquitin ligases, two of which (Cull and Cul3) target $\beta$-catenin and Dishevelled (Angers et al. 2006) for de- 
struction, respectively, and thus function, at least in part, antagonistically to the Wnt pathway. The Cul4 proteins use an adaptor protein, Ddb1 (UV damage-specific DNA-binding protein 1), which associates with a diverse group of WD40 proteins that contain a 16-amino-acid motif called the DWD box (Ddb1 binding and WD40 repeat) (Higa and Zhang 2007). The large DWD class of WD40 proteins (>100 in humans) are substrate selectivity receptors that use their distinctive WD40 domains to recruit proteins that are destined for ubiquitylation-destruction by Cul4A, although on occasion the WD40 protein itself is targeted for degradation (He et al. 2006; Lee and Zhou 2007).

One well-characterized target of the Cul4:Ddb1 complex is the Ddb2 WD40 protein, which promotes polyubiquitylation of the nucleotide excision repair protein Xeroderma pigmentosum group C (XPC) to regulate global genome repair. The Cul4A:Ddb1:Ddb2 complex also controls the turnover of the chromatin-bound DNA replication licensing factor, Cdt1, which is maintained at low levels to prevent DNA rereplication. Another substrate is the Cockayne's syndrome B (CSB) protein on stalled RNA Polymerase II complexes, which connects to Cul4:Ddb1 through the Cockayne's syndrome A (CSA) WD40 protein, and regulates transcriptioncoupled repair.

The Cul4A:Ddb1:Ddb2 complex also monoubiquitinates core histones in response to UV-induced DNA damage, and ubiquitylation of histones $\mathrm{H} 3$ and $\mathrm{H} 4$ promotes XPC-mediated repair of damaged DNA (Dai and Wang 2006; Wang et al. 2006). Other WD40 proteins known to interact with Cul4A:Ddb1 include the WDR5 and RBBP5 subunits of the MLL-1 (mixed lineage leukemia)/Setd1 complex, which mediates H3K4me3, an epigenetic mark of gene activation (Higa et al. 2006). Interestingly, siRNA-mediated knockdown of Cul4A or Ddb1, like WDR5, significantly reduces global levels of mono- and trimethylated H3K4 in HeLa cells. Cul4A also associates with EED/ESC, a WD40 subunit of the EZH2 (Enhancer of Zeste homolog 2) histone methyltransferase complex to promote $\mathrm{H} 3 \mathrm{~K} 9 \mathrm{me} 3$ and $\mathrm{H} 3 \mathrm{~K} 27 \mathrm{me}$, and affects the formation and spread of heterochromatin in vivo (Jia et al. 2005). It would be interesting to learn whether activation of Cul4A in Wnt-induced mammary tumors, or in colon cancer cells where the Wnt pathway is permanently induced, is accompanied by sustained global changes in histone methylation that might contribute to cell transformation.

\section{Does Cul4A:Ddb1 target other proteins in Wnt signaling cells?}

The effect of Cul4A on histone methylation, particularly H3K4me3, also raises the question of whether this E3 ligase might influence Wnt $/ \beta$-catenin transcription. Indeed, $\beta$-catenin physically associates with the MLL-1/ Setd 1 complex and stimulates H3K4me3 at the $c-M y c$ gene in vivo (Sierra et al. 2006), and the $\beta$-catenin coactivator, Pygopus, is a PHD finger protein that binds directly to H3K4me2,3 (Fiedler et al. 2008). Previous stud- ies have also shown that Cul4A:Ddb1 interacts directly with TLE-1/Groucho (Higa et al. 2006), a WD40 repeat protein that represses Wnt target gene transcription in nonsignaling cells through binding to LEF-1/TCF proteins in the corepressor complex. Thus long-term expression of active Cul4A could lead to the ubiquitylation destruction of TLE1-bound LEF-1/TCF or associated corepressors in Wnt-expressing tumors and constitutively derepress Wnt target genes.

TBL1 and TBLR1 are WD40-F-box repeat proteins related to TLE-1/Groucho and contain the DWD motif that mediates binding to Cul4A:Ddb1 (He et al. 2006). These proteins function at nuclear receptor-regulated genes to mediate the ubiquitin-conjugating/19S proteasome-dependent exchange of coactivator and corepressor complexes at target promoters (Perissi et al. 2004). A recent study found that TBL1 and TBLR1 are recruited to Wnt target genes and promote transcription by stabilizing the binding of the $\beta$-catenin:LEF-1/TCF complex to chromatin (Li and Wang 2008). Thus the Cul4A:Ddb1 ubiquitin ligase might in principle target proteins associated with the TBL1:TBLR1 WD40 proteins and block coregulator exchange. In this respect, it is interesting to note that the APC tumor suppressor, which, like TBL1 and TBLR1, has also been implicated in the cyclic exchange of coregulator complexes at Wnt target genes in vivo (Sierra et al. 2006).

\section{Both Cul4:Ddb1 and Wnt signaling affect the mTOR pathway}

The Wnt signaling pathway not only affects gene transcription through $\beta$-catenin but also controls protein translation through activation of the mTOR signaling pathway (Inoki et al. 2006). mTOR signaling is regulated by the tuberous-sclerosis TSC1/2 complex, a potent tumor suppressor that inhibits translation through the mTOR complex proteins (for review, see Huang and Manning 2008). Previous work has shown that TSC 2 activity requires phosphorylation by GSK3 $\beta$ and the AMPactivated protein kinase, AMPK (Inoki et al. 2006). Inhibition of GSK3 $\beta$ activity in Wnt signaling cells blocks TSC2 phosphorylation and greatly reduces its activity, which induces mTOR, a master regulator of cell growth and cell size that controls translation $10 \%-15 \%$ of cellular genes. Activated mTOR is a critical mediator of Wnt-induced cell growth, and inhibition of mTOR by rapamycin blocks the formation of Wnt-induced tumors in vivo. Wnt induction of mTOR requires GSK3, Axin, and APC but is independent of $\beta$-catenin and does not require ongoing transcription (Inoki et al. 2006). Interestingly, GSK3-mediated phosphorylation of TSC2 may take place within the $\beta$-catenin destruction complex. Physical interaction studies show that TSC2 associates with GSK3 and Axin in nonsignaling cells and then switches to associate with Dishevelled in Wnt signaling cells (Mak et al. 2005). In this model, disruption of the destruction complex and inhibition of GSK3 in TSC-related tissues inactivates TSC2 and enables mTOR signaling. 
Several studies have suggested a role for Cul4A in mTOR signaling. mTOR signaling requires the $26 \mathrm{~S}$ proteasome, and Cul4 interacts with the mTOR complex subunit Raptor (Ghosh et al. 2008). Moreover, binding of Cul4A to the FBW5 WD40 protein ubiquitylates TSC2 for destruction, thereby inducing mTOR signaling (Hu et al. 2008). Thus, in principle, Wnt-induced Cul4 activity in tumors might eventually degrade the TSC2 tumor suppressor and permanently up-regulate the mTOR pathway. Additional studies have shown that the TSC1/2 proteins negatively regulate steady-state levels of $\beta$-catenin, consistent with their association with GSK $3 \beta$ and Axin within the $\beta$-catenin destruction complex (Mak et al. 2003), and induces Wnt signaling in tuberous sclerosis (Mak et al. 2005). Although entirely speculative, these published data raise the possibility that Cul4:Ddb1 could play a direct role in Wnt signaling by changing $\beta$-catenin levels, chromatin structure and transcription, or mTOR-dependent translation of growth control genes.

In this respect, it should be noted that although Cul4A and Cul4B mRNA levels are clearly elevated in Wnt10binduced tumors, it is not clear that this is the sole mechanism responsible for the observed increase in Cul4:Ddb1 activity in Wnt signaling cells. For example, it is not known whether ongoing transcription and $\beta$ catenin are required for the Wnt-induced degradation of p27, nor is it known whether dominant-negative LEF/ TCF proteins would block p27 degradation. As an aside, the presence of $\beta$-catenin and LEF/TCF at the Cul4A gene promoter does not fully qualify Cul4A as a direct Wnt target gene, because it is not clear that this binding site is a regulatory element for Cul4A transcription. Thus these data do not exclude the possibility that, in addition to increasing transcription of the Cul4A gene, Wnt signaling might also directly up-regulate Cul4A:Ddb1 E3 ligase activity in vivo. Cul4A is known to be activated by post-translational neddylation, and its ligase activity can be inactivated by a deneddylase subunit present in the COP9 signalosome. This issue is of particular interest because direct changes in the neddylation state or activity of Cul4A could allow it to act as an "immediate responder" to transient Wnt signaling, in addition to its transcriptional up-regulation in constitutive Wnt-expressing tumors.

\section{Perspectives}

The study of Mirandi-Carboni et al. (2008) firmly establishes Cul4A as the E3 ligase responsible for the destruction of p27 in Wnt10b-induced mammary tumors in vivo and in Wnt signaling mammary tissues and cells and, most importantly, identifies Cul4:Ddb1 as a Wnt-induced ubiquitin ligase. Based on these findings, the investigators propose that inhibitors of Cul4A ligase activity could be useful therapeutics for the relatively large subgroup of human breast cancers that express low levels of both p27 and Skp2. However, the cellular context of p27 regulation is also likely to be an important consideration for therapeutic approaches. For example, inhi- bition of GSK3 and induction of Wnt/ $\beta$-catenin signaling was shown recently to stabilize $\mathrm{p} 27^{\mathrm{Kip} 1}$ protein levels and block $M L L$ oncogene-dependent proliferation and transformation in human $M L L$ leukemia cells (Wang et al. 2008), in contrast to the destabilization of p27 observed in breast and colorectal cells.

The study by Miranda-Carboni et al. (2008) raises many interesting questions for follow-up studies, including the identity of the DWD-WD40 protein that links p27 to the Cul4A:Ddb1 complex in Wnt signaling cells (Fig. 1). As mentioned above, much remains to be learned of the broader role of Cul4 ubiquitylation in Wnt tumors, including the identity of other WD40 substrate adaptors attached to Cul4A:Ddb1 in these cells, potentially including TLE-1/Groucho, TBL1/TBLR1, and TSC2, and what effects these additional targets of Cul4A may have on Wnt transformation. A major question is whether Cul4A associates with the intact $\beta$-catenin destruction complex, and, if so, how it is targeted there and how it might function within the complex. Lastly, it would be useful to know whether Wnt signaling up-regulates Cul4A activity directly, and, if so, whether this affects early signaling steps, including the fate and function of the destruction complex. Future studies of this new Wnt-induced proteolytic targeting system may therefore continue to provide valuable insight into the control of cell growth in Wnt-transformed tumors.

\section{Acknowledgments}

We thank Jamie Simon for the expert artwork, and our colleagues in the laboratory for comments on this review. Our laboratory studies the mechanism of Wnt-induced transcription, funded through the NIH (CA125535) and the Hewitt Foundation for Medical Research.

\section{References}

Angers, S., Thorpe, C.J., Biechele, T.L., Goldenberg, S.J., Zheng, N., MacCoss, M.J., and Moon, R.T. 2006. The KLHL12-Cullin-3 ubiquitin ligase negatively regulates the Wnt- $\beta$-catenin pathway by targeting Dishevelled for degradation. Nat. Cell Biol. 8: 348-357.

Barker, N., van de Wetering, M., and Clevers, H. 2008. The intestinal stem cell. Genes \& Dev. 22: 1856-1864.

Blanpain, C., Horsley, V., and Fuchs, E. 2007. Epithelial stem cells: Turning over new leaves. Cell 128: 445-458.

Bondar, T., Kalinina, A., Khair, L., Kopanja, D., Nag, A., Bagchi, S., and Raychaudhuri, P. 2006. Cul4A and Ddb1 associate with Skp2 to target p27Kip1 for proteolysis involving the COP9 signalosome. Mol. Cell. Biol. 26: 2531-2539.

Cang, Y., Zhang, J., Nicholas, S.A., Bastien, J., Li, B., Zhou, P., and Goff, S.P. 2006. Deletion of DDB1 in mouse brain and lens leads to p53-dependent elimination of proliferating cells. Cell 127: 929-940.

Chu, I.M., Hengst, L., and Slingerland, J.M. 2008. The Cdk inhibitor p27 in human cancer: Prognostic potential and relevance to anticancer therapy. Nat. Rev. Cancer 8: 253-267.

Dai, Q. and Wang, H. 2006. Cullin 4 makes its mark on chromatin. Cell Div. 1: 14. doi: 10.1186/1747-1028-1-14.

Fiedler, M., Sanchez-Barrena, M.J., Nekrasov, M., Mieszczanek, J., Rybin, V., Muller, J., Evans, P., and Bienz, M. 2008. De- 
coding of methylated histone $\mathrm{H} 3$ tail by the Pygo-BCL9 Wnt signaling complex. Mol. Cell 30: 507-518.

Ghosh, P., Wu, M., Zhang, H., and Sun, H. 2008. mTORC1 signaling requires proteasomal function and the involvement of CUL4-DDB1 ubiquitin E3 ligase. Cell Cycle 7: 373381.

Grigoryan, T., Wend, P., Klaus, A., and Birchmeier, W. 2008. Deciphering the function of canonical Wnt signals in development and disease: Conditional loss- and gain-of-function mutations of $\beta$-catenin in mice. Genes \& Dev. 22: 23082341.

He, Y.J., McCall, C.M., Hu, J., Zeng, Y., and Xiong, Y. 2006. DDB1 functions as a linker to recruit receptor WD40 proteins to CUL4-ROC1 ubiquitin ligases. Genes \& Dev. 20: 2949-2954.

Higa, L.A. and Zhang, H. 2007. Stealing the spotlight: CUL4DDB1 ubiquitin ligase docks WD40-repeat proteins to destroy. Cell Div. 2: 5. doi: 10.1186/1747-1028-2-5.

Higa, L.A., Wu, M., Ye, T., Kobayashi, R., Sun, H., and Zhang, H. 2006. CUL4-DDB1 ubiquitin ligase interacts with multiple WD40-repeat proteins and regulates histone methylation. Nat. Cell Biol. 8: 1277-1283.

Howe, L.R. and Brown, A.M. 2004. Wnt signaling and breast cancer. Cancer Biol. Ther. 3: 36-41.

Hu, J., Zacharek, S., He, Y.J., Lee, H., Shumway, S., Duronio, R.J., and Xiong, Y. 2008. WD40 protein FBW5 promotes ubiquitination of tumor suppressor TSC2 by DDB1-CUL4ROC1 ligase. Genes \& Dev. 22: 866-871.

Huang, H. and He, X. 2008. Wnt/ $\beta$-catenin signaling: New (and old) players and new insights. Curr. Opin. Cell Biol. 20: 119125.

Huang, J. and Manning, B.D. 2008. The TSC1-TSC2 complex: A molecular switchboard controlling cell growth. Biochem. $J$. 412: 179-190.

Inoki, K., Ouyang, H., Zhu, T., Lindvall, C., Wang, Y., Zhang, X., Yang, Q., Bennett, C., Harada, Y., Stankunas, K., et al. 2006. TSC2 integrates Wnt and energy signals via a coordinated phosphorylation by AMPK and GSK3 to regulate cell growth. Cell 126: 955-968.

Jia, S., Kobayashi, R., and Grewal, S.I. 2005. Ubiquitin ligase component Cul4 associates with Clr4 histone methyltransferase to assemble heterochromatin. Nat. Cell Biol. 7: 10071013.

Lane, T.F. and Leder, P. 1997. Wnt-10b directs hypermorphic development and transformation in mammary glands of male and female mice. Oncogene 15: 2133-2144.

Lee, J. and Zhou, P. 2007. DCAFs, the missing link of the CUL4-DDB1 ubiquitin ligase. Mol. Cell 26: 775-780.

Li, J. and Wang, C.Y. 2008. TBL1-TBLR1 and $\beta$-catenin recruit each other to Wnt target-gene promoter for transcription activation and oncogenesis. Nat. Cell Biol. 10: 160-169.

Lindvall, C., Bu, W., Williams, B.O., and Li, Y. 2007. Wnt signaling, stem cells, and the cellular origin of breast cancer. Stem Cell Rev. 3: 157-168.

Mak, B.C., Takemaru, K., Kenerson, H.L., Moon, R.T., and Yeung, R.S. 2003. The tuberin-hamartin complex negatively regulates $\beta$-catenin signaling activity. J. Biol. Chem. 278: 5947-5951.

Mak, B.C., Kenerson, H.L., Aicher, L.D., Barnes, E.A., and Yeung, R.S. 2005. Abberrant $\beta$-catenin signaling in tuberous sclerosis. Am. J. Pathol. 167: 107-116.

McCartney, B.M. and Näthke, I.S. 2008. Cell regulation by the Apc protein Apc as a master regulator of epithelia. Curr. Opin. Cell Biol. 20: 186-193.

Miranda-Carboni, G.A., Krum, S.A., Yee, K., Nava, M., Deng,
Q.E., Pervin, S., Collado-Hidalgo, A., Galić, Z., Zack, J.A., Nakayama, K., et al. 2008. A functional link between Wnt signaling and SKP2-independent p27 turnover in mammary tumors. Genes \& Dev. (this issue). doi: 10.1101/ gad.1692808.

Nusse, R. and Varmus, H.E. 1982. Many tumors induced by the mouse mammary tumor virus contain a provirus integrated in the same region of the host genome. Cell 31: 99-109.

O'Connell, B.C. and Harper, J.W. 2007. Ubiquitin proteasome system (UPS): What can chromatin do for you? Curr. Opin. Cell Biol. 19: 206-214.

Perissi, V., Aggarwal, A., Glass, C.K., Rose, D.W., and Rosenfeld, M.G. 2004. A corepressor/coactivator exchange complex required for transcriptional activation by nuclear receptors and other regulated transcription factors. Cell 116: 511526.

Philipp-Staheli, J., Kim, K.-H., Payne, S.R., Gurley, K.E., Liggitt, D., Longton, G., and Kemp, C.J. 2002. Pathway-specific tumor suppression: Reduction of p27 accelerates gastrointestinal tumorigenesis in Apc mutant mice, but not in Smad3 mutant mice. Cancer Cell 1: 355-368.

Reya, T. and Clevers, H. 2005. Wnt signaling in stem cells and cancer. Nature 434: 843-850.

Reya, T., Morrison, S.J., Clarke, M.F., and Weissman, I.L. 2004. Stem cells, cancer, and cancer stem cells. Nature 414: 105111.

Sierra, J., Yoshida, T., Joazeiro, C.A., and Jones, K.A. 2006. The APC tumor suppressor counteracts $\beta$-catenin activation and H3K4 methylation at Wnt target genes. Genes \& Dev. 20: 586-600.

Timmerbeul, I., Garrett-Engele, C.M., Kossatz, U., Chen, X., Firpo, E., Grunwald, V., Kamino, K., Wilkens, L., Lehmann, U., Buer, J., et al. 2006. Testing the importance of p27 degradation by the $\mathrm{SCF}^{\mathrm{Skp} 2}$ pathway in murine models of lung and colon cancer. Proc. Natl. Acad. Sci. 103: 14009-14014.

Tsukamoto, A.S., Grosschedl, R., Guzman, R.C., Parslow, T., and Varmus, H.E. 1988. Expression of the int-1 gene in transgenic mice is associated with mammary gland hyperplasia and adenocarcinomas in male and female mice. Cell 55: 619625.

Wang, H., Zhai, L., Xu, J., Joo, H.Y., Jackson, S., ErdjumentBromage, H., Tempst, P., Xiong, Y., and Zhang, Y. 2006. Histone $\mathrm{H} 3$ and $\mathrm{H} 4$ ubiquitylation by the CUL4-DDBROC1 ubiquitin ligase facilitates cellular response to DNA damage. Mol. Cell 22: 383-394.

Wang, Z., Smith, K.S., Murphy, M., Piloto, O., Somervaille, T.C., and Cleary, M.L. 2008. Glycogen synthase kinase 3 in $M L L$ leukaemia maintenance and targeted therapy. Nature 455: 1205-1209. 


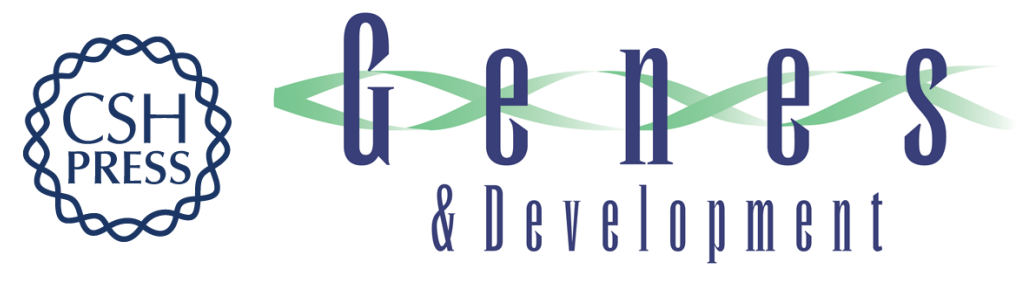

\section{Wnt-induced proteolytic targeting}

Katherine A. Jones and Caroline R. Kemp

Genes Dev. 2008, 22:

Access the most recent version at doi:10.1101/gad.1741008

\section{Related Content A functional link between Wnt signaling and SKP2-independent p27 turnover in mammary tumors \\ Gustavo A. Miranda-Carboni, Susan A. Krum, Kathleen Yee, et al. \\ Genes Dev. November , 2008 22: 3121-3134 \\ References This article cites 38 articles, 10 of which can be accessed free at: \\ http://genesdev.cshlp.org/content/22/22/3077.full.html\#ref-list-1 \\ Articles cited in: \\ http://genesdev.cshlp.org/content/22/22/3077.full.html\#related-urls \\ License \\ Email Alerting Receive free email alerts when new articles cite this article - sign up in the box at the top Service right corner of the article or click here.}

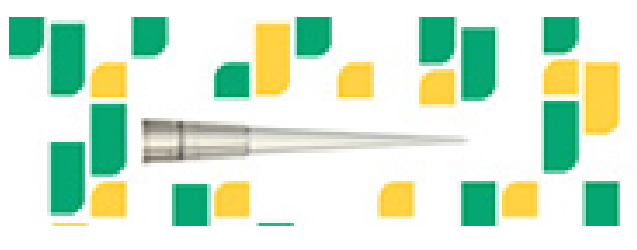

Focused on your science. 